\title{
Prevalence and rate of diagnosis of allergic rhinitis in Europe
}

\author{
V. Bauchau*, S.R. Durham ${ }^{\#}$
}

Prevalence and rate of diagnosis of allergic rhinitis in Europe. V. Bauchau, S.R. Durham. (C) ERS Journals Ltd 2004.

ABSTRACT: To measure the prevalence of allergic rhinitis among European adults and the proportion of undiagnosed subjects, a two-step, cross-sectional, populationbased survey in Belgium, France, Germany, Italy, Spain, and the UK was undertaken.

Step one of the study involved screening for allergic rhinitis by telephone interview, based on history of symptoms and/or self-awareness of the condition. Step two undertook confirmation of allergic rhinitis in a subset of the subjects screened positive; this was performed by a clinical diagnosis conducted in three to five clinical centres per country, including specific immunoglobulin $\mathbf{E}$ tests and a disease-specific questionnaire.

A total of 9,646 telephone interviews were conducted between February and April 2001. Self-awareness of allergic rhinitis was reported by $19 \%$ of the subjects. Physicianbased diagnosis of allergic rhinitis was reported by $13 \%$ of the subjects. In step two, 725 clinical assessments were conducted between May and August 2001. A total of 411 of patients, who underwent step two, had investigator-confirmed allergic rhinitis. Among patients with investigator-confirmed allergic rhinitis, $45 \%$ had not reported a previous diagnosis by a physician. Prevalence of subjects with clinically confirmable allergic rhinitis estimated by combining step one and step two data ranged from $17 \%$ in Italy to $29 \%$ in Belgium with an overall value of $23 \%$.

This large-scale study confirms that allergic rhinitis has a high prevalence in western Europe and is frequently undiagnosed.

Eur Respir J 2004; 24: 758-764.
*UCB Pharma S.A., R\&D, Clinical Epidemiology and Outcomes Research, Chemin du Foriest, Braine-l' Alleud, Belgium. "Faculty of Medicine, Imperial College, National Heart and Lung Institute, London, UK.

Correspondence: V. Bauchau, UCB Pharma S.A., R\&D, Clinical Epidemiology and Outcomes Research, Chemin du Foriest, B-1420, Braine-1' Alleud, Belgium.

Fax: 3223863197

E-mail: vincent.bauchau@ucb-group.com

Keywords: Epidemiology intermittent allergic rhinitis persistent allergic rhinitis prevalence underdiagnosis

Received: February 32004

Accepted after revision: August 152004

The study was funded by UCB Pharma, Braine-l'Alleud, Belgium.
Allergic rhinitis is a common disorder, which represents a considerable burden both on individual patients and society [1]. It is associated with bothersome symptoms, which may impair usual daily activities, quality of sleep and productivity [2]. Frequently, allergic rhinitis is associated with comorbidities including asthma [3, 4]. Overall, the quality of life is significantly impaired in subjects with allergic rhinitis $[5,6]$, but can be improved by treatment [7]. Indeed, early detection and optimal treatment are emphasised in guidelines [1]. However, the condition may frequently be trivialised (by the patient) and/or unrecognised (by the physician), resulting in the inadequate control of symptoms. In the UK, only $18 \%$ of subjects with rhinitis had visited their general practitioner, over the preceding 2 yrs, concerning their hay fever [8]. A recent study in France showed that $19 \%$ of 230 patients with typical symptoms of allergic rhinitis had never consulted a physician for their nasal problem [9].

There are few large-scale, standardised studies of the prevalence of allergic rhinitis in Europe. For the adult population, the European Community Respiratory Health Survey (ECRHS) found that the overall prevalence of allergic rhinitis was $21 \%$ [10]. This study was largely concerned with asthma and, although there were many interesting findings on allergic rhinitis, its purpose was not to look at the rate of diagnosis of this condition. The diagnosis rate for allergic rhinitis has only been measured in studies that have been limited in terms of the studied populations and/or had restricted geographical coverage. The proportion of undiagnosed subjects was relatively high, ranging from $25-60 \%$ [11-13].
The objective of the present survey was to perform a comprehensive study of the prevalence of allergic rhinitis in western Europe, and to test whether the relatively high rate of underdiagnosis, found in small studies, might be confirmed by a large-scale, multi-national, standardised, population-based study. A key point to the current study was that prevalence was estimated both for diagnosed cases and for clinically confirmable cases, defined as subjects in the general population who would be diagnosed with allergic rhinitis if they would present to a physician, irrespective of the presence or absence of a previous diagnosis. This is also the first largescale study to measure the prevalence of sub-types of allergic rhinitis as recently defined by Allergic Rhinitis and its Impact on Asthma (ARIA) [1].

\section{Methods}

\section{Study design}

The study was cross-sectional, population-based, and included countries throughout western Europe. It was designed to include samples as representative of the general population as possible and to have the ability to identify previously undiagnosed cases. The study was divided into two consecutive, integrated steps. In step one, telephone interviews of randomly chosen adult subjects were conducted to measure prevalence of allergic rhinitis and to screen potential subjects with allergic rhinitis. In step two, all subjects who 
screened positive for allergic rhinitis, and who agreed to participate, were examined by a clinical investigator for a potential diagnosis of allergic rhinitis.

\section{Step one: telephone interviews}

The target population were subjects living in private households, aged $\geqslant 18$ yrs. In each country, four to five areas were chosen; each had a maximum radius of $50 \mathrm{~km}$ from a clinical centre.

The sampling procedure involved the following: in each country a database of 16,000 (Germany: 25,000) phone numbers was used to obtain a target sample of 1,600 interviews; the phone numbers in the database were obtained by randomly sampling telephone directories or by randomly altering the last four digits of existing telephone numbers (as undertaken in the UK).

Interviews took place typically during weekdays from 17:00-21:00 $\mathrm{h}$ and during the weekend from 10:00-18:00 h. A telephone number was not abandoned before a minimum number of attempts (3-30, depending on the country) had been made, on different occasions.

To obtain a sample representative of the general population, the persons to be interviewed were also selected according to quotas of sex and age (and working status in the UK). Within each household, a person was randomly selected according to a pre-set procedure, such as being the last person having had his/her birthday. When the person selected in the household did not belong to the quota, another household was used (not another person in the same household).

The phone interviews had a mean duration of $10 \mathrm{~min}$. The questionnaire was specifically designed for the study, partly based on existing and well-validated questionnaires [14]. The French version of the questionnaire was tested for clarity and sensitivity in a small sample of the general population in Belgium. Each translation (English, German, Italian, Spanish and Dutch) was tested for clarity in a small sample of subjects (five to 10) from each country. There were a total of 20 closeended questions.

Subjects were scored positive if at least one of the following was true: 1) having reported two or more nasal symptoms (when not suffering from a cold or flu); 2) having reported one nasal symptom and either concurrent eye symptom or specific trigger; and 3) having reported being self-aware of having allergic rhinitis.

The aim of this screening algorithm was to be highly sensitive in order to avoid false negatives.

At the end of the interview, all subjects with a positive score on the screening algorithm were invited to participate in step two of the study. Subjects were not compensated for participating in step one of the study. During the telephone call, subjects were asked to answer a short survey on some aspects of their health, but the focus on rhinitis was not revealed before they had accepted and started the interview. This minimises the influence that selection bias for having rhinitis symptoms (or not) would have on the results.

The presence of a previous physician-based diagnosis was assessed at step one. If the patient reported suffering from hay fever, nasal allergy, allergic rhinitis or allergic rhinoconjunctivitis, and if the patient reported they had learnt about this condition from a physician, then the patient was classified as having a previous physician-based diagnosis. Otherwise (patient not reporting having an allergic rhinitis, or patient reporting having allergic rhinitis but not having been told so by a physician) the patient was classified as not having a previous physician-based diagnosis.

\section{Step two: clinical diagnosis}

Step two consisted of a clinical examination, which included specific immunoglobulin (Ig) E measurements and a disease-specific questionnaire. Subjects received compensation to cover travel costs.

The clinical diagnosis was performed by local investigators, who were instructed to establish a diagnosis according to their usual practice. A total of 26 clinical centres were selected, with the aim to cover as much geographical variability as possible within each country (fig. 1). All investigators in the UK were general practitioners; all investigators in Spain and Italy were specialists. In the three other countries (Belgium, France, and Germany), there were a mixture of general practitioners (one or two per country) and specialists (two to four per country).

A sample of blood was taken and sent to a central laboratory for IgE testing. The Pharmacia-CAP system (Pharmacia Diagnostics, Uppsala, Sweden) was used to measure specific IgE for six groups of allergens: grass, tree and weed pollens, animal danders, moulds and dust mites. For grass, tree and weed pollens, the investigator was instructed to select one among a panel of three to five tests, according to local pollens. All six tests were a mix of several allergens, except for Olive tree and Parietaria, which were offered as options in the panel for tree and weed pollen, respectively. For the present analyses, subjects were considered as sensitised to a given group of allergens if the measurements of $\mathrm{IgE}$ were $\geqslant 0.35 \mathrm{kU} \cdot \mathrm{L}^{-1}$.

The second, disease-specific questionnaire was self-administered during the visit to the clinical centre. This questionnaire was designed for the study. The French version of the questionnaire was tested for clarity and validity in a small sample of the general population in Belgium. Each translation (English, German, Italian, Spanish and Dutch) was tested for clarity in a small sample of subjects (five to 10) from the specific country. There were a total of 40 questions; the questionnaire was designed to be self-administered and to be completed within 20 min.

Severity of symptoms was measured on a four-point verbal descriptor scale (0: no problem; 1 : problem present but not disturbing; 2: disturbing problem but not hampering certain

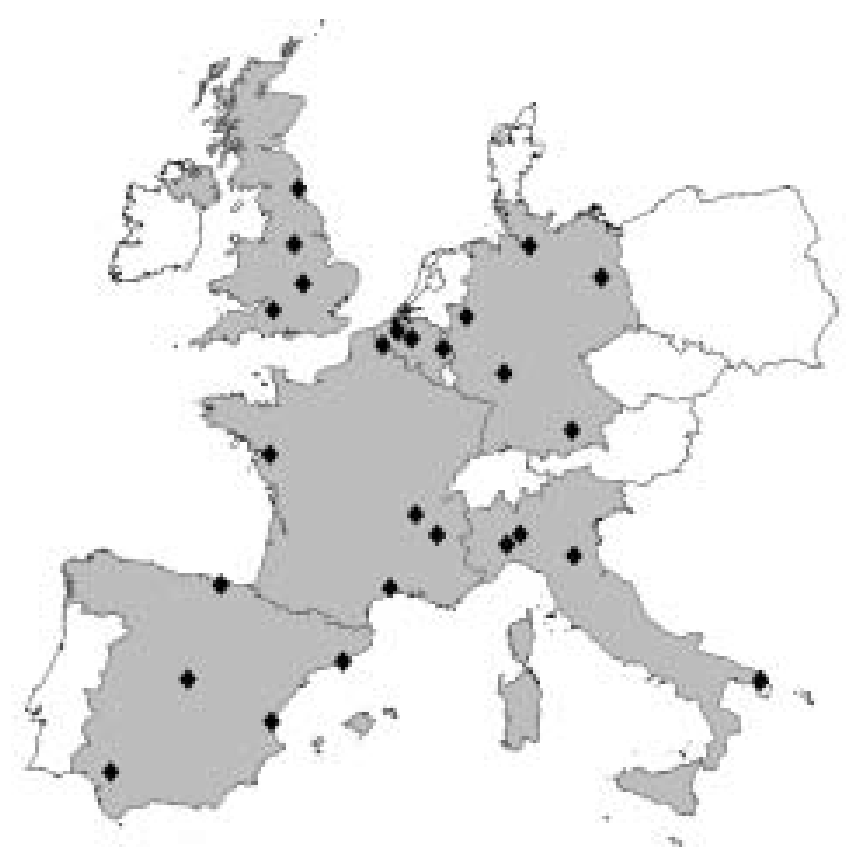

Fig. 1.- Location of study centres. $\bullet$ : study centres. 
activities or sleep; 3 : problem hampering certain activities or sleep).

\section{Rhinitis classification}

The new ARIA classification [1] was used to classify allergic rhinitis as persistent if the symptoms were present during $\geqslant 4$ days a week and during $\geqslant 4$ weeks consecutively. It was otherwise classified as intermittent. Frequency of symptoms (days per week; consecutive weeks per yr) were reported at step one. Subjects participating in step two and diagnosed with allergic rhinitis were classified as seasonal allergic rhinitis (SAR), perennial allergic rhinitis (PAR), or both, by the investigator.

\section{Statistics}

Univariate comparisons of two samples were performed by Wilcoxon-Mann-Whitney test or Chi-squared test of contingency. Raw confidence intervals (CI) of proportions were based on the binomial distribution with alpha $=0.05$.

Odds ratios (OR) were estimated by univariate and multivariable logistic regression. For multivariable logistic regression analyses, a Hierarchical Backwards Elimination strategy was used [15]: the full model incorporated factors selected for their statistically significant relationship with the outcome (in univariate tests) and/or their epidemiological relevance; key two-way interactions were included and removed if nonsignificant; remaining main factors were then removed if not significant, and the changes in parameters (ORs) were also assessed at each step. For the prevalence of

Step one: telephone interviews

Telephone interviews $n=9646(1600-1625$ per country)

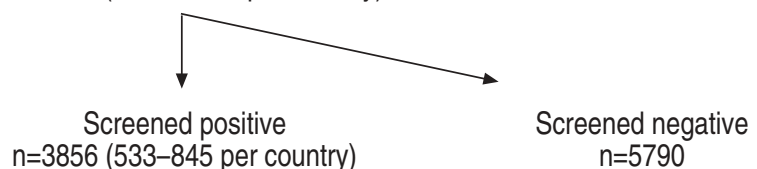
$n=5790$

Step two: clinical investigations

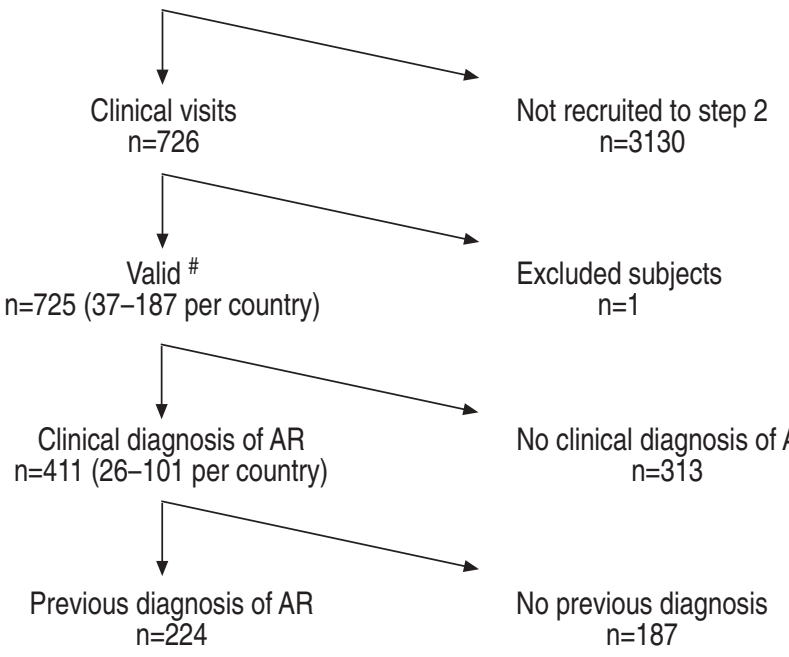

Fig. 2. - Study flow chart. AR: allergic rhinitis. ${ }^{\#}$ : includes one subject with missing investigator-based diagnosis, and one subject with missing immunoglobulin E measurements.

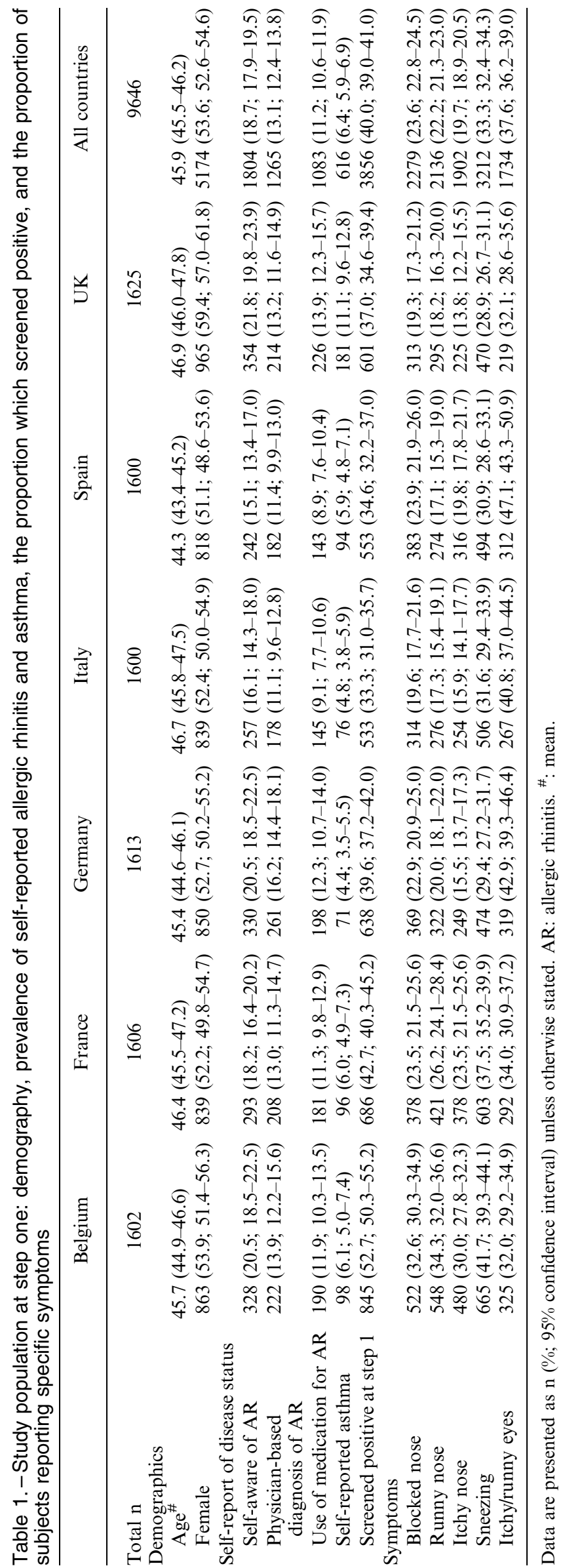


subjects with clinically confirmable allergic rhinitis, which is a product of two proportions, the variance for the calculation of the $95 \%$ CI was computed using the variance of a product of two random variables [16]; bootstrapping produced similar results.

\section{Ethics}

Approval was obtained from ethics or scientific committees for each country and study centre. All subjects participating in step two had signed an informed consent.

\section{Results}

\section{Sample sizes}

Figure 2 shows the sample sizes of the different steps and subgroups in the study.

\section{Step one: telephone interviews}

Telephone interviews were carried out from February to April 2001. The target number of 1,600 subjects was obtained in each country (table 1). Missing or out-of-range values were extremely rare and were mostly birth dates $(0.6 \%$ missing).

The demographic structure of the sampled population from each country (table 1) was compared with national demographical statistics by age and sex. Only small and nonsignificant deviations were found, except for two cases where the discrepancies were worth noting, these were: 1) in the UK, there was an excess number of females in the age class $35-59$ yrs $(49 \%$ of female in the study sample compared with $41 \%$ in the national statistics); and 2) in Germany, there was an excess of both sexes in the age class $35-49$ yrs (44\% of the subjects in this age class compared with $28 \%$ in the national statistics).

Self-awareness of having allergic rhinitis was reported by $19 \%$ of the subjects, while $13 \%$ ( $70 \%$ of the self-aware) reported having received a physician-based diagnosis of allergic rhinitis; $11 \%$ reported taking medication for allergic rhinitis (table 1). Variations between the countries was large; the prevalence of self-reported allergic rhinitis was highest in the UK, Germany and Belgium and lowest in Spain and Italy, with France having intermediate values (table 1). The proportion of self-reported current asthma was $6.4 \%$ overall (table 1 ) and $22 \%$ (272 out of 1,265$)$ among the subjects who reported a physician-based diagnosis of allergic rhinitis.

Overall, $40 \%(3,856$ out of 9,646$)$ of the subjects were positive on the screening algorithm and were, therefore, invited to take part in step two of the study (the clinical examination). The proportion was noticeably higher in Belgium than in the other countries (table 1).

\section{Step two: clinical examinations}

A total of 726 subjects participated in step two, by completing a visit to a clinical centre, between May and August 2001; only one subject was excluded from all analyses because a different person had answered the interview (fig. 2).

Subjects who attended or did not attend step two were compared for the variables that could have an effect on further estimates of the prevalence of allergic rhinitis and the rate of diagnosis (table 2). The following factors were positively associated with participation in step two: male sex, younger age, self-awareness of allergic rhinitis, previous diagnosis or medication for allergic rhinitis, having persistent allergic rhinitis, having reported nasal or eye symptoms; however, association was generally weak (ORs ranging from 0.74-1.8). A multivariable logistic analysis (details not shown) demonstrated that all these factors were independently associated with participation.

Investigators diagnosed allergic rhinitis in 411 of the 724 subjects $(57 \%)$ who attended visits to clinical centres during step two. The most common clinical diagnoses in the other subjects $(n=313)$ were: vasomotor rhinitis, nonallergic rhinitis, infections, anatomical abnormalities, and sinusitis; the pattern was similar for those who had reported a previous diagnosis of allergic rhinitis that was not confirmed at step two $(n=63)$.

Specific IgE were detected for at least one group of tested allergens in $83 \%$ of the subjects with a clinical diagnosis of allergic rhinitis. The most frequently detected allergen was grass pollen $(52 \%$ of the subjects with clinical diagnosis of allergic rhinitis), followed by house dust mite $(49 \%)$, tree pollen $(33 \%)$, weed pollen $(27 \%)$, animal danders $(26 \%)$, and mould spores $(10 \%)$. The proportion of subjects sensitised to

Table 2. - Comparison of demographic and self-reported characteristics between subjects who were scored positive at step one and who attended or did not attend step two of the study

\begin{tabular}{|c|c|c|c|c|}
\hline & $\begin{array}{l}\text { Patients who did } \\
\text { not attend step } \\
\text { two of the study }\end{array}$ & $\begin{array}{l}\text { Patients who } \\
\text { attended step } \\
\text { two of the study }\end{array}$ & Total $\mathrm{n}$ & $\begin{array}{l}\text { Risk of attending } \\
\text { study at step two } \\
\text { OR }(95 \% \text { CI })\end{array}$ \\
\hline Patients $n$ & 3131 & 725 & 3856 & \\
\hline $\mathrm{Age}^{\#}$ & 42.6 & 40.4 & 3846 & $0.992(0.987-0.997)^{\bullet}$ \\
\hline Females & $1759(56.2)$ & $354(48.8)$ & 3856 & $0.744(0.633-0.875)$ \\
\hline Self-aware of AR & $1418(45.3)$ & $386(53.2)$ & 3856 & $1.376(1.170-1.617)$ \\
\hline Physician-based diagnosis of $\mathrm{AR}$ & $978(31.2)$ & $287(39.6)$ & 3856 & $1.442(1.221-1.705)$ \\
\hline Medication use for AR & $822(26.3)$ & $261(36.0)$ & 3856 & $1.580(1.331-1.875)$ \\
\hline Persistent allergic rhinitis & $615(20.1)$ & $191(26.8)$ & 3776 & $1.453(1.204-1.753)$ \\
\hline Disease duration $\leqslant 5 \mathrm{yrs}^{+}$ & $510(36.2)$ & $130(33.8)$ & 1794 & $0.899(0.709-1.140)$ \\
\hline Runny nose & $1547(49.4)$ & $460(63.4)$ & 3856 & $1.777(1.505-2.100)$ \\
\hline Blocked nose & $1521(48.6)$ & $438(60.5)$ & 3852 & $1.618(1.372-1.908)$ \\
\hline Itchy nose & $1392(44.5)$ & $401(55.4)$ & 3850 & $1.547(1.314-1.820)$ \\
\hline Sneezing & $2208(70.6)$ & $533(73.7)$ & 3852 & $1.170(0.975-1.405)$ \\
\hline Itchy/runny eyes & $1360(47.0)$ & $374(54.0)$ & 3588 & $1.328(1.125-1.569)$ \\
\hline Number of symptoms & 2.8 & 3.2 & 3575 & $1.327(1.239-1.421)^{\S}$ \\
\hline
\end{tabular}

Data presented as $n(\%)$ unless otherwise stated. OR: odds ratio; CI: confidence interval; AR: allergic rhinitis. ${ }^{\#}$ : mean; ${ }^{\circ}$ : change in odds OR for one additional year; ${ }^{+}$: disease duration available only for subjects self-aware of AR; ${ }^{\S}$ : change in OR for one additional symptom. 
at least one outdoor (grass, tree, weed) allergen was $63 \%$; the proportion of subjects sensitised to at least one indoor (dust mites, animal, mould) allergen was $55 \%$; a total of $34 \%$ were sensitised to at least one indoor and one outdoor allergen.

The subjects with clinical diagnosis of allergic rhinitis were classified by the investigators into SAR and/or PAR, and classified into intermittent or persistent (ARIA definition) based on self-reports of symptoms (table 3).

Among patients with a clinical diagnosis of allergic rhinitis, $31 \%$ were not aware of having such a condition and $45 \%$ had not reported a previous diagnosis by a physician, ranging from $30 \%$ in Italy to $54 \%$ in France (table 3).

As expected, the rate of clinical diagnosis of allergic rhinitis in step two was much higher in subjects with a previous diagnosis (224 out of $287=78 \%$ received a clinical diagnosis, confirming the previous diagnosis) than in subjects with no previous diagnosis (187 out of $437=43$ ).

For $85 \%$ (350 out of 411$)$ of the subjects with a clinical diagnosis of allergic rhinitis, the investigator stated that a medication should be given. Among those subjects who should take a medication, according to the physician, $47 \%$ (164 out of 350) reported not having used any medication for allergic rhinitis over the past 2 yrs. Among those who should take a medication and were previously diagnosed, $21 \%$ (43 out of 204) had not used medication; conversely, $83 \%$ (121 out of 146) among those with no previous diagnosis.

Current asthma was self-reported by $20.4 \%$ ( 84 out of 411 ) of the subjects with a clinical diagnosis of allergic rhinitis, compared with $3.9 \%$ (12 out of 300 ) of the subjects without such a diagnosis.

Subjects who reported or did not report a previous physician-based diagnosis were compared (table 4). Crude ORs suggest that the following factors were positively associated with the risk of being diagnosed: female sex, not smoking, self-reporting asthma, having seasonal allergic rhinitis, having persistent allergic rhinitis, disease duration $>5 \mathrm{yrs}$, having disturbing symptoms (runny nose, sneezing and irritated eyes), having symptoms exacerbated on exposure to outdoor triggers, and having positive IgE tests (any allergen but mould). A logistic regression analysis was performed with these factors, except disease duration (not available for all subjects); for IgE tests and symptom severity, composite variables (table 4) were used for greater efficiency. Country was initially introduced in the model, but was found not to be significant and was therefore removed. After removing all other nonsignificant factors, the final model demonstrated the independent effect of being female (adjusted OR: $1.61 ; 95 \%$ CI: 1.03-2.53), self-reported asthma (2.29; $1.28-4.08)$, having persistent allergic rhinitis $(1.69 ; 1.03-2.77)$, higher symptom severity score $(1.73 ; 1.20-2.50)$, symptoms exacerbated by exposure to outdoor triggers $(2.52 ; 1.61-3.94)$, and larger number of positive IgE tests $(1.21 ; 1.05-1.41)$.

The prevalence of subjects with clinically confirmable allergic rhinitis in the general population was estimated by combining information from step one and step two of the study. The estimation was the product of the proportion of subjects with a positive score (step one) by the proportion of subjects with positive score and a clinical diagnosis of allergic rhinitis (step two). The prevalence of subjects with clinically confirmable allergic rhinitis ranged from $17 \%$ in Italy to $29 \%$ in Belgium, with an overall value 23\% (table 5). The overall prevalence was also computed with stratification by population size ( $\geqslant 18 \mathrm{yrs}$ ) in each country, resulting in an estimate of $22 \%$, corresponding to 53 million people.

Because subjects with a previous diagnosis of allergic rhinitis were more likely to participate in step two of the study, and were also more likely to obtain a clinical diagnosis of allergic rhinitis, the prevalence of subjects with clinically confirmed allergic rhinitis was also estimated with adjustment 
Table 4.-Comparison of characteristics of subjects with clinical diagnosis of allergic rhinitis at step two of the study, who reported, or did not report, a previous physician-based diagnosis of allergic rhinitis and crude odds ratios (OR) for the risk of being diagnosed with allergic rhinitis

\begin{tabular}{|c|c|c|c|c|}
\hline & $\begin{array}{l}\text { Undiagnosed } \\
\text { patients }\end{array}$ & $\begin{array}{c}\text { Diagnosed } \\
\text { patients }\end{array}$ & Total $\mathrm{n}$ & Crude OR $(95 \% \mathrm{CI})$ \\
\hline Patients $\mathrm{n}$ & 187 & 224 & 411 & \\
\hline $\mathrm{Age}^{\# \cdot \Phi}$ & 38.1 & 36.8 & 411 & $0.992(0.978-1.007)$ \\
\hline Female & $78(41.7)$ & $116(51.8)$ & 411 & $1.501(1.015-2.220)$ \\
\hline Employed & $20(19.4)$ & $25(15.5)$ & 264 & $0.763(0.399-1.459)$ \\
\hline Smokers & $67(35.8)$ & $51(22.8)$ & 411 & $0.528(0.343-0.814)$ \\
\hline Self-reported asthma & $24(12.8)$ & $60(26.8)$ & 411 & $2.485(1.476-4.182)$ \\
\hline SAR & $80(42.8)$ & $122(54.5)$ & 411 & $1.600(1.082-2.366)$ \\
\hline ARIA persistent ${ }^{+}$ & $40(21.6)$ & $79(35.7)$ & 406 & $2.017(1.292-3.148)$ \\
\hline Disease duration $\leqslant 5 \mathrm{yrs}^{\S}$ & $24(41.4)$ & $58(25.9)$ & 282 & $0.495(0.271-0.904)$ \\
\hline Runny nose (disturbing) & $78(42.9)$ & $139(62.6)$ & 404 & $2.233(1.497-3.332)$ \\
\hline Blocked nose (disturbing) & $103(56.6)$ & $128(59.3)$ & 398 & $1.116(0.748-1.663)$ \\
\hline Itchy nose (disturbing) & $55(30.6)$ & $84(38.2)$ & 400 & $1.404(0.924-2.132)$ \\
\hline Sneezing (disturbing) & $68(37.2)$ & $131(59.0)$ & 405 & $2.435(1.629-3.638)$ \\
\hline Irritated eyes (disturbing) & $74(41.1)$ & $126(57.0)$ & 401 & $1.900(1.275-2.831)$ \\
\hline Total severity score $\#, f$ & 1.3 & 1.6 & 411 & $2.305(1.655-3.210)$ \\
\hline \multicolumn{5}{|l|}{ Symptoms on exposure } \\
\hline Indoor & $79(42.2)$ & $112(50.0)$ & 411 & $1.367(0.925-2.021)$ \\
\hline Outdoor & $76(40.6)$ & $159(71.0)$ & 411 & $3.573(2.370-5.385)$ \\
\hline Family history of allergic rhinitis & $62(38.0)$ & $92(46.0)$ & 363 & $1.388(0.911-2.114)$ \\
\hline Family history of any allergic conditions & $117(69.6)$ & $141(68.1)$ & 375 & $0.931(0.600-1.446)$ \\
\hline Registration with GP & $149(82.3)$ & $170(79.4)$ & 395 & $0.830(0.500-1.376)$ \\
\hline Travel to physician difficult & $16(8.9)$ & $29(13.6)$ & 394 & $1.607(0.843-3.064)$ \\
\hline \multicolumn{5}{|l|}{ Positive IgE test } \\
\hline Grass pollen & $80(42.8)$ & $134(60.1)$ & 410 & $2.014(1.357-2.988)$ \\
\hline Tree pollen & $47(25.1)$ & $90(40.4)$ & 410 & $2.016(1.318-3.084)$ \\
\hline Weed pollen & $35(18.7)$ & $76(34.1)$ & 410 & $2.245(1.417-3.557)$ \\
\hline Mould & $19(10.2)$ & $22(9.9)$ & 410 & $0.968(0.507-1.849)$ \\
\hline Animal & $36(19.3)$ & $69(30.9)$ & 410 & $1.879(1.185-2.981)$ \\
\hline Dust mites & $83(44.4)$ & $117(52.5)$ & 410 & $1.383(0.936-2.043)$ \\
\hline Number of positive tests $\# \#$ & 1.6 & 2.3 & 410 & $1.340(1.171-1.533)$ \\
\hline
\end{tabular}

Data are presented as $\mathrm{n}(\%)$ unless otherwise stated. CI: confidence interval; SAR: seasonal allergic rhinitis; GP: general practitioner; Ig: immunoglobulin. ${ }^{\#}$ : mean; ${ }^{\circ}$ : change in OR for one additional year; ${ }^{+}$: as classified by Allergic Rhinitis and its Impact on Asthma (ARIA) study; disease duration available only for subjects self-aware of allergic rhinitis; ${ }^{f}$ : change in OR for one additional unit on the mean severity score; ${ }^{\# \#}$ : change in OR for one additional positive IgE test.

for previous diagnosis. As expected, the adjusted prevalence is lowered, but not significantly (overall prevalence was $22 \%$; details not shown).

\section{Discussion}

The main result of this study is the confirmation of the high prevalence of allergic rhinitis throughout western Europe and the relatively low rate of diagnosis. The prevalence of allergic rhinitis was estimated in two ways. First, the telephone interviews (step one) indicated that 19\% of the subjects were aware of having allergic rhinitis and 13\% had a physicianbased diagnosis. This approach had the advantage of little

Table 5.-Prevalence of clinically confirmable allergic rhinitis

\begin{tabular}{lc}
\hline Country & Prevalence \\
\hline Belgium & $28.5(24.5-32.5)$ \\
France & $24.5(21.0-28.0)$ \\
Germany & $20.6(16.5-24.6)$ \\
Italy & $16.9(12.9-20.9)$ \\
Spain & $21.5(18.5-24.4)$ \\
UK & $26.0(20.3-31.7)$ \\
All countries & $22.7(21.1-24.2)$
\end{tabular}

Data are presented as $\%(95 \%$ confidence interval $)$. bias in the population sampled and large sample sizes. Conversely, the information was only self-reported with no clinical confirmation. The prevalence of self-awareness obtained by this approach $(19 \%)$ was close to the prevalence in ECRHS study (21\%) [10], obtained with a similar methodology. A younger population (20-44 yrs) could explain the larger estimate in the latter study; indeed, the prevalence in the current study in the same age group is $23 \%$. In both studies, the prevalence was highest in northern countries (e.g. UK and Belgium) and lowest in southern countries (e.g. Spain and Italy).

The second estimate of the prevalence of allergic rhinitis in the general population was obtained by combining information from steps one and two of the study. Here the proportion of subjects with clinically confirmable allergic rhinitis were estimated, i.e. subjects who either had a previous diagnosis of allergic rhinitis that would be confirmed by a physician or who were not previously diagnosed but would be diagnosed with allergic rhinitis if they would present to a physician. This estimate (22 or $23 \%$ overall, depending on adjustment) was based on more reliable clinical data (step two of the study) but on a smaller sample which may be more biased by the recruitment stage.

In the current study, the proportion of undiagnosed subjects was estimated to be $45 \%$. This relatively high figure is within the range of previous but more limited studies. SiBBALD and RINK [13] examined 7,702 adults registered with a group of general practices based in London, UK. Subjects 
with SAR were twice as likely, compared with those with perennial PAR, to be labelled as having rhinitis by their doctor. More than one-quarter of those with hay fever had not been diagnosed as such, whereas approximately one-half of the patients with PAR were not diagnosed. In another series of 813 postal questionnaires, $46 \%$ of the subjects who reported symptoms of allergic rhinitis had not been diagnosed as such by a physician [12]. Similarly, a recent study in Poland among a random sample of 1,522 inhabitants of Lodz found that $50 \%$ of the subjects with SAR and $61 \%$ of the subjects with PAR had not been diagnosed by a medical practitioner [11]. As expected, only part of the subjects invited to take part in step two of the current study (i.e. visit to clinical centres) participated $(725$ out of 3,$856 ; 19 \%$ ) and this is a potential source of bias. However, subjects with a previous diagnosis were more likely to participate, suggesting that the estimate found in the present study of the proportion of undiagnosed subjects, if biased, is likely to be underestimated.

Subjects who were previously diagnosed could be characterised as having more severe symptoms and more visible symptoms (seasonal symptoms, symptoms that could be linked to specific triggers, and concurrent asthma) as compared with subjects not previously diagnosed. Employment and access to medical resources did not appear to be a factor for the presence or absence of a diagnosis. This suggests that the absence of diagnosis, in a large part of the population, is probably related to other factors, such as lack of information. Undiagnosed subjects had lower symptom severity, but not for the most burdensome symptom blocked nose. Severity for the other symptoms was still not negligible. Indeed, for most of the undiagnosed subjects, the investigators recommended the use of medication.

The new classification of allergic rhinitis proposed by the ARIA initiative is relatively recent [1] and prevalence data are rare. In France, $49 \%$ of patients consulting for allergic rhinitis were classified as having persistent allergic rhinitis [17]. In the current study, on a larger geographical scale and in an unselected population, approximately one-third of the subjects with allergic rhinitis had persistent allergic rhinitis.

In conclusion, allergic rhinitis is common in western Europe, affecting more than one out of five adults. This condition is frequently undiagnosed and, although undiagnosed subjects had somewhat less severe symptoms, they could nevertheless benefit from a proper diagnosis and treatment.

\section{References}

1. Bousquet J, Van Cauwenberge P, Khaltaev N, Aria Workshop Group, World Health Organization. Allergic rhinitis and its impact on asthma. J Allergy Clin Immunol 2001; 108: Suppl. 5, S147-S334.

2. Crystal-Peters J, Crown WH, Goetzel RZ, Schutt DC. The cost of productivity losses associated with allergic rhinitis. Am J Manag Care 2000; 6: 373-378.

3. Spector SL. Overview of comorbid associations of allergic rhinitis. J Allergy Clin Immunol 1997; 99: S773S780.

4. Leynaert B, Bousquet J, Neukirch C, Liard R, Neukirch F. Perennial rhinitis: an independent risk factor for asthma in nonatopic subjects: results from the European Community Respiratory Health Survey. J Allergy Clin Immunol 1999; 104: 301-304.

5. Bousquet J, Bullinger M, Fayol C, Marquis P, Valentin B, Burtin B. Assessment of quality of life in patients with perennial allergic rhinitis with the French version of the SF-36 Health Status Questionnaire. J Allergy Clin Immunol 1994; 94: 182-188.

6. Leynaert B, Neukirch C, Liard R, Bousquet J, Neukirch F. Quality of life in allergic rhinitis and asthma. A populationbased study of young adults. Am J Respir Crit Care Med 2000; 162: 1391-1396.

7. Tripathi A, Patterson R. Impact of allergic rhinitis treatment on quality of life. Pharmacoeconomics 2001; 19: 891-899.

8. Jones NS, Smith PA, Carney AS, Davis A. The prevalence of allergic rhinitis and nasal symptoms in Nottingham. Clin Otolaryngol 1998; 23: 547-554.

9. Didier A, Chanal I, Klossek JM, Mathieu J. La rhinite allergique: le point de vue du patient. Revue Française Allergologie 1999; 39: 171-185.

10. Janson C, Anto J, Burney P, et al. The European Community Respiratory Health Survey: what are the main results so far? European Community Respiratory Health Survey II. Eur Respir J 2001; 18: 598-611.

11. Kuprys I, Elgalal A, Korzycka-Zaborowska B, Gorski P, Kuna P. Underdiagnosis of allergic diseases in the general population of Lodz province. Allergy 2002; 57: Suppl. 73, 185.

12. Richards S, Thornhill D, Roberts H, Harries U. How many people think they have hay fever, and what they do about it. Br J Gen Pract 1992; 42: 284-286.

13. Sibbald B, Rink E. Labelling of rhinitis and hayfever by doctors. Thorax 1991; 46: 378-381.

14. Charpin D, Sibbald B, Weeke E, Wuthrich B. Epidemiologic identification of allergic rhinitis. Allergy 1996; 51: 293-298.

Acknowledgements. The authors would like to thank all the subjects and investigators for their participation to this study. They have benefited greatly from several colleagues: D. Strachan contributed to the design and early interpretation of the study results; C. Arrigo contributed to the study design, conduct, interpretation and reporting; D. Philippart contributed to the analysis; C. Otoul suggested several improvements on the manuscript.
15. Kleinbaum DG, Klein M. Logistic regression. 2nd Edn. Berlin, Springer-Verlag, 2002.

16. Dagnelie P. Théorie et méthodes statistiques [Statistical theory and methods]. Gembloux, Presses Agronomiques de Gembloux, 1973.

17. Demoly P, Allaert FA, Lecasble M, Bousquet J, PRAGMA. Validation of the classification of ARIA (allergic rhinitis and its impact on asthma). Allergy 2003; 58: 672-675. 